\title{
Veterans' civilian employment experiences: Lessons learnt from focus groups
}

Accepted for Publication by Journal of Career Development March 2018.

Keeling, M., Ozuna, S., Kintzle, S., \& Castro, C.A.

\begin{abstract}
Emerging evidence highlights employment as a key factor influencing the success of transition from military to civilian life. Historically, employment programs have focused on improving skills such as resume writing and interview skills. However, it is likely that employment challenges are more than these practical barriers. Four focus groups with employed and unemployed Gulf War era II veterans were conducted aimed at moving past a practical perspective by gaining experiential understandings of veterans' employment. Thematic analysis indicated that the veterans' employment experiences were best understood temporally in two master themes: Pretransition and the divergent experiences of veterans who did and did not plan ahead; and, Living the transition and the veterans' experiences of employment barriers and facilitators. Further to the two master themes an underlying thread of the need for self-determination was evident. Interpretation of the results led to the development of recommendations for policy, service provision, and future research.
\end{abstract}

Key words: Veterans; Employment; Military transition; Unemployment. 


\section{Veterans' civilian employment experiences: Lessons learnt from focus groups}

Employment is a key social determinant of health and unemployment is a key determinant of health inequalities, likely leading to psychological distress and material deprivation, which may cause strain on family and social relationships (Hamilton, Williams, \& Washington, 2015). As conflicts in Iraq and Afghanistan have drawn to an end and a defense drawdown is reported by the Department of Defense Budget 2016 (Department of Defense, 2015), it is likely that the number of veterans leaving service and re-entering civilian employment is set to increase.

In 2015, there were 21.1 million veterans in the U.S., accounting for approximately 9 percent of the civilian non-institutional population age 18 and over (Bureau of Labor Statistics, 2016). While the statistics reported by the Bureau of Labor Statistics (BLS) indicate that the unemployment rate between veterans and non-veterans are only marginally and not significantly different, except among younger (aged 24 -25 years), these statistics may be misleading.

The BLS statistics should, be interpreted with caution since they are derived from the Current Population Survey (CPS) which surveys 60,000 households each month, thus it is cross-sectional data, and usually contains only a small percentage of veterans, meaning unemployment estimates may not be precise (Loughran, 2014). Purpose built survey research of veterans, indicates that the majority leave service without a civilian job in place, expecting to quickly find meaningful employment that provides adequate and expected pay and benefits (Castro, Kintzle, \& Hassan, 2014). Underemployment among veterans however, is reported to be a challenge faced by many who have jobs, yet earn below the poverty line or are in entry level jobs that do not utilize their skills, knowledge or capabilities (Barrera \& Carter, 2017; Castro et al., 2014). Loughran (2014) proposes that the period following initial discharge from the military, is when unemployment is highest since veterans are currently searching for work and is a critical period for finding 
employment. Current literature proposes some explanations for the employment problems and the challenges some veterans may face.

\section{Veteran health and employment}

Mental health difficulties have consistently been shown in various veteran and non-veteran studies to be associated with unemployment. Studies focusing specifically on veteran populations consistently find that depression and anxiety are associated with unemployment, but find no association between Post-Traumatic Stress Disorder (PTSD) and unemployment (Hamilton et al., 2015; Horton et al., 2013; Zivin et al., 2016). Research with human resource professionals found that, whilst the majority reported being willing to employ veterans with PTSD and Traumatic Brain Injury (TBI), several reported believing that employing veterans with mental health problems would involve more costs, more manager time, and were unsure if veterans with PTSD or TBI were more likely than others to be violent in the work place (Rudstam, Strobel Gower, \& Cook, 2012). Physical health problems are also likely to cause difficulties finding and maintaining employment. However, the BLS report states that the rate of unemployment among veterans with a service connected disability who are in the workforce is 5.4 percent, which is not statistically different to those with no disability (Bureau of Labor Statistics, 2016).

\section{The military-civilian cultural gap}

Due to the possible unfamiliarity with military service, civilian employers may struggle to understand the different roles and training of military service thus, making it hard to assess how a veterans' military experience may be transferrable to a civilian job (Carter, Schafer, Kidder, \& Fagan, 2017). Moreover, both veterans and employers may struggle to translate military experience in to comparable civilian credentials (Kintzle et al., 2015; Prudential, 2012). For example an Executive Officer of an Army unit who is second-in-command reporting to the commanding office, is responsible for the management of day-to-day activities, freeing the 
commander to concentrate on strategy, and planning a unit's next move. In civilian terms, this job would translate to a Chief of Staff or Operations manager role. However, it is possible that many veterans would not be familiar with the civilian job role titles or how to describe their military duties and experiences in terms understandable to civilian employers and relevant to the civilian jobs.

Other military-civilian cultural differences may also create barriers for veterans finding and maintaining civilian employment. Military communication is marked by frequent use of acronyms, direct command orientated exchanges, and nuances in vocabulary and colloquialisms (Shields, Kuhl, Frender, Baurmann, \& Lopresti, 2016). Mismatch in communication and being misunderstood can lead to feelings of invalidation, in turn creating challenges with social relationships, identity, belongingness, and self-esteem (Shields et al., 2016; Smith \& True, 2014). The civilian work environment is often characterized by individualism, autonomy, and creativity, which might be perceived as representing a lack of discipline to veterans who are used to working in a collective environment with clear structure (Atuel, Keeling, Kintzle, Hassan, \& Castro, 2016).

\section{Veteran discrimination}

Those who have served in areas of war and combat may experience discrimination when seeking employment in the civilian sector due to common misperceptions, associated stereotypes, or readjustment issues (Kleykamp, 2009; Rudstam et al., 2012). Kleykamp's (2009) vignette study of possible employer discrimination found that the hiring of veterans differed by race and military work experiences. Veterans portrayed in job applications as being black and having an administrative role whilst in the military were treated more favorably than matched civilian peers. Black veterans with combat experiences were substantially disadvantaged compared to matched civilians; this was true for white combat veterans too. White veterans with equivalent clerical work 
experiences were treated the same as non-veterans with comparable experience. Although Kleykamp's (2009) study found some evidence for the existence of employer discrimination against combat veterans, the method used means Kleykamp (2009) cautions for these results to be interpreted as suggestive, not conclusive.

\section{Current employment programs}

Due to the various barriers military personnel may face in securing and maintaining employment post military service, prior to transition, military personnel are mandated to attend Transition GPS (Goals, Plans, Success) which is the Department of Defense (DOD) Transition Assistance Program (TAP). TAP is designed to build skills to assist service members in being "career ready" when they leave service. The core curriculum of TAP includes Military Occupational Code (MOC) Crosswalk to demonstrate how to translate military skills, training and experience into civilian jobs; financial planning; benefits briefings; and, a Department of Labor Employment Workshop (including learning interview skills, resume writing, and job search skills), which should all result in the development of an Individual Transition Plan (ITP) review (Department of Defense, 2016). The provision of TAP indicates that the DOD is aware of the importance of service leavers making plans and setting goals for a successful transition to civilian life and employment. However, the experiences of veterans applying what they learnt in TAP and the effectiveness of TAP for setting veterans for civilian employment success are less well known.

Whilst this existing research goes some way in providing information about veterans' unemployment, there is limited research focusing on veterans' experiences of finding and maintaining civilian employment. Qualitative data, such as produced when focus groups are conducted, can help to gain an experiential understanding of veteran unemployment and what factors and experiences may play a role in veterans' search for and maintenance of civilian 
employment. The aim of the current study was to gain experiential data from veterans about their civilian employment experiences since leaving military service to discern the obstacles they faced and how they overcame them during their attempts to find and maintain civilian employment.

\section{Method}

\section{Participant recruitment}

The aim was to recruit participants to one of six focus groups; three groups consisting of currently employed veterans and three of currently unemployed veterans. Only Gulf war era II veterans were eligible for the study due to the differences of the employment needs of veterans from different eras. Participants who completed the (detail removed for blind review) (a survey of veterans living in the Chicago Metropolitan area defined as Cook, Depage, Will, and Lake counties) and who agreed to be re-contacted regarding future research were emailed a study information sheet and invited to participate. Veterans interested in taking part were asked to reply to the email to express their interest. Veterans who emailed expressing their interest were contacted to confirm their current employment status and the era they served. Depending on employment status and the availability of the veterans on the days and times the researchers would be conducting the focus groups, the veterans chose either an employed or unemployed group that best

fitted their schedule. Where veterans had flexibility the researchers attempted to distribute participants by gender to try to ensure there was a gender mix in all groups. Due to the slow uptake of participants to the study, researchers also contacted potential participants via telephone to improve recruitment. 


\section{Sample}

Despite the aim to recruit participants to one of six focus groups, small numbers of veterans volunteering to take part meant only five focus groups were filled $(3 \mathrm{x}$ employed groups; $2 \mathrm{x}$ unemployed groups). A large contributing factor to low recruitment may have been the focus groups being conducted in a Downtown Chicago location; some veterans who were invited declined stating that car parking was too expensive. Unfortunately, several veterans who had agreed to take part via email or telephone conversation did not attend in person at the designated time and place. Therefore, the final sample for the study comprised three employed focus groups and one unemployed focus group; none of the participants recruited for the second unemployed group attended and only two out of an expected eight participants, for one of the employed groups, attended on the day. The final total sample $(n=18)$ of focus groups included both male and female veterans (male $n=12$ and female $n=6$ ) and all service branches were represented. All participants were Gulf war era II veterans (Gulf war era II veterans are those who served since September 2001), though three of the four veterans in the unemployed group as reserves during Gulf war era II, following previous active duty during Gulf war era I (Table 1).

Table 1 Overview of focus group participants

\begin{tabular}{lrrrrr} 
& Employed 1 & Employed 2 & Employed 3 & Unemployed & Total \\
\hline N & 4 & 2 & 8 & 4 & 18 \\
Gender & 3 & 1 & 6 & 2 & 12 \\
$\quad$ Male & 1 & 1 & 2 & 2 & 6 \\
$\quad$ Female & & & & & \\
$\begin{array}{l}\text { Service } \\
\text { Navy }\end{array}$ & 3 & - & 2 & 1 & 6 \\
$\quad$ Army & - & 1 & 2 & 3 & 6 \\
$\quad$ Marine & 1 & - & 3 & - & 4 \\
$\quad$ Air Force & -21 & $4-6$ & 1 & - & 2 \\
$\quad \begin{array}{l}\text { Years served* } \\
\begin{array}{l}\text { Years since } \\
\text { discharge }\end{array}\end{array}$ & $5-6$ & $6-8$ & $<1-9$ & $2-13$ & $4-21$ \\
*Total years served includes time as reserve and active duty in employed group 2 and unemployed group &
\end{tabular}




\section{Materials}

Two digital voice recorders were used to record all focus groups. A semi-structured question schedule was created by the research team to guide the focus groups to address the aim of the study. As per guidelines for the semi-structured schedules, the questions were worded to be open ended to encourage participants to provide full responses and the opportunity to share their experiences without the restraints of existing response options. The following main questions were included in the schedule, each question included prompts if participants did not understand or had trouble responding:

1. What planning/preparations did you make in the run up to you leaving the military?

2. What were your expectations?

3. What if anything would you have changed about how your approached your transition out of the military?

4. What initial steps did you take to find employment once you had left the military?

5. Tell us about your experiences finding a job

6. What were your initial experiences in your first civilian job?

7. What were your experiences of civilian employment?

8. What support service did you use?

9. What support services would you have liked to use?

10. How might employers help veterans to find and maintain employment? 


\section{Procedure}

Focus groups took place at (Location removed for blind review). Groups organized for those who were employed were conducted in the evenings and groups for those who were unemployed were held during the day time. Focus groups lasted approximately 1.5 hours and all participants were provided a $\$ 30$ cash incentive for taking part. Following completion of the focus groups, audio recordings of the groups were transcribed verbatim to allow for in-depth analysis.

\section{Analysis}

Thematic analysis was conducted to address the research aim of investigating the employment experiences of veterans in the Chicago Metropolitan area. Thematic analysis is a qualitative research methodology used to identify and interpret patterns or themes within the data (Braun \& Clarke, 2008). This type of qualitative approach allows focus at the experiential level, allowing for a deeper understanding of veteran's employment experiences. To go some way in ensuring confirmability of the results and interpretations, two of the researchers analyzed the focus groups independently in the first instance, meeting at key stages through the process to compare and discuss their analysis and interpretations.

Thematic analysis began with a close line by line examination of the data that led to codes being identified. Codes were then considered for similarities and differences and how they may naturally be grouped together or showed opposing views leading to the development of themes. Once themes had been developed for each focus group, by each of the two researchers, they met to compare and discuss their individual analyses. Differences and similarities in their interpretations were highlighted and agreement sought following a discussion regarding how and why the various codes and themes had been derived. A focus was on ensuring that all 
interpretations came from the participants accounts. Verbatim quotes were identified which exemplified each theme to ensure authenticity and credibility of the themes and interpretations. This discussion lead to master themes being identified for each of the four individual focus groups. Having developed master themes for each individual focus group, the two researchers independently considered the convergence and divergence of themes across all four focus groups, eventually leading to each of the two researchers developing master themes for the entire data set. The two researchers met again to compare the master themes they had developed, engaging in a similar discussion as before, ensuring agreement on interpretation and labelling of the sub-themes and master themes.

The final master themes were presented and discussed with the other two authors who had read some of the transcripts and been involved in data collection SK and CC. this process assisted the researchers to ensure that the findings were derived from the data and participants' experiences and not due to preconceived bias or expectations of the researchers. Agreement of the identified master themes and sub-themes was reached and it was believed that interpretations and themes had been developed from the data, as evidence by the verbatim quotes. At all stages of the research process, researchers were mindful to ensure that emerging codes and themes came from the participants and not the researchers pre-existing expectations, motivations, or interests.

\section{Ethics}

This study was approved by the (Removed for blind review) Institutional Review Board (IRB). It was perceived that there was only the potential of minimal risk to participants and all participants were assured of the confidential nature of the focus groups and the data which was anonymized during transcription. All participants were informed and reminded of their right to 
withdraw from the focus group at any point during data collection and their right to decline response to any questions.

\section{Results}

Thematic analysis of four focus groups with veterans, investigating their experiences of finding and maintaining employment since leaving the military, indicated that the employment experiences of the veterans were best understood temporally, leading to the development of two master themes: Pre-Transition and Living the Transition. These two master themes were identified inductively from the data through thematic analysis, not guided by existing theory or previous studies. These two themes are however, similar to the stages of transition specified in Military Transition Theory (Castro, Kintzle, \& Hassan, 2015) even though this theory did not drive the analysis. Due to the nature of the topic of veteran employment being experienced during a transition period, it is unsurprising that the veterans' experiences can be understood in temporal terms. Further to the two master themes, an underlying thread of "self-determination, motivation, and drive" was identified as being important both before and during transition to aid success in finding and maintaining employment. This underlying thread was identified as it emerged as a defining feature of those who had been more successful in finding and maintaining employment both before leaving the military and since leaving. Each of the themes and their corresponding sub-themes are discussed, exemplifying the importance of the underlying thread in each theme. Themes and subthemes are shown in table two supported by verbatim quotes from the focus group transcripts which provide evidence of the truth and credibility of these findings. 
Table 2 Verbatim quotes of each master theme and sub-themes

\section{Master theme and Supporting quotes from focus group transcripts sub-themes}

\section{Pre-transition}

Thinking ahead

Not thinking ahead

$$
\begin{aligned}
& \text { "When I got off active duty in 2000, I caught myself setting myself up for } \\
& \text { success...I got my Bachelor's degree before I got out, that was one of the goals } \\
& \text { I set for myself. The Navy has a really good, what they call, TAP...lets you know } \\
& \text { all the benefits you could qualify for...veteran associations and groups..." } \\
& \text { (Male - Employed group 1) } \\
& \text { "I knew what I wanted to do before I got out so I started preparing two years } \\
& \text { in advance. And I wanted to go into PR because that's basically what I did in } \\
& \text { the marines. So I found other veterans that were in PR and I followed their } \\
& \text { footstpes and it was an easy transition for me." (Female - Employed group 3) } \\
& \text { "I thought. It wasn't a lot and I was } 23 \text { years old. I didn't know better. I didn't } \\
& \text { think about it...You can go through that (TAPS) but I just kind of checked the } \\
& \text { box, showed up and left" (Male - Employed group 2) } \\
& \text { "My experience was different...the Navy put us in a base in Mississippi that had } \\
& \text { no real support....the TAP classes that they mentioned were very limited to the } \\
& \text { group I was with. A lot of the benefits weren't there. So the things we should } \\
& \text { have been given....we didn't have the opportunity for that. So when we got out, } \\
& \text { it's a lot of us, were searching" (Male - employed group 1) }
\end{aligned}
$$

\begin{tabular}{|c|c|}
\hline Barriers & $\begin{array}{l}\text { "A lot of it has been equating the leadership and management skills that I learned } \\
\text { in the military and equating in to a civilian sector. I think that was one of my } \\
\text { anxieties about transitioning out... The question was, what I've learned for the } \\
\text { last } 20 \text { years, how is that gonna, you know, equate to the civilian world. And the } \\
\text { lingo is different than, you know... and I have a very low tolerance for people } \\
\text { that don't have a strong work ethic." (Female - Unemployed group) } \\
\text { "I thought it would be easy to transition to law enforcement, but instead I found } \\
\text { it more a hindrance... because they would look at your combat service... oh we } \\
\text { don't want you, you're too much of a risk...they wouldn't' say it directly but I } \\
\text { would get letters, 'we've chosen someone else." (Male - Employed group 3). }\end{array}$ \\
\hline \multirow[t]{3}{*}{ Facilitators } & $\begin{array}{l}\text { "Nowadays connections is everything...there's always a veteran's outreach } \\
\text { program out there, you just got to go find them" (Female - employed group 2) }\end{array}$ \\
\hline & $\begin{array}{l}\text { "That's what it was for me the first couple of months just learning how to talk } \\
\text { different to people" (Male - employed group 1) }\end{array}$ \\
\hline & $\begin{array}{l}\text { "One of the things I love about working in film is the fact that it's always team } \\
\text { players and it's like continuing on that sense of camaraderie because the whole } \\
\text { team makes a film, and just continuing to do that is like giving me a sense of } \\
\text { purpose outside the military" (Male - employed group 3). }\end{array}$ \\
\hline
\end{tabular}

\section{Living the transition}




\section{Pre-transition}

It was evident that a dichotomy of experiences existed between those who had thought about the future and made plans and preparations and those who had not thought ahead, nor made any plans or preparations for life after the military. Thus, Pre-transition is characterized by the opposing sub-themes "Thinking ahead" and "Not thinking ahead". These sub-themes were derived inductively from the data and these categorizations have not been used in other studies, to the authors knowledge. The thread of self-determination, motivation and drive was most evident here as differentiating those who did think ahead from those who did not.

Thinking ahead: Ten of the 18 veterans discussed the ways in which they had thought ahead and started to make plans for their employment or education when they left the military. This was represented by veterans who "knew what they wanted to do" before they left the military such as "I knew I wanted to go to college" or "I knew I wanted a career not just a job", to more specific future goals such as wanting to join the police force or work in public relations. Veterans who reported thinking about their future prior to leaving the military spent time planning and preparing such as connecting with potential future employers and applying for jobs, making contact with veterans already in the field they wished to work, talking to veteran peers about the reality of civilian life, and making financial considerations such as planning their finances to support a return to education or saving money to support them during the initial job search period. Thus, the veterans who thought ahead showed self-determination (Ryan \& Deci, 2000), motivation and drive to succeed in life after the military. A key defining feature of the veterans who had "thought ahead" was voicing positive appraisals of the Transition Assistance Program (TAP) stating they found it extremely useful and engaging. By thinking ahead, these veterans mostly had 
realistic expectations of what life after military service would be like and had been in consistent employment since leaving the military.

Not thinking ahead: The eight veterans who had not thought ahead had not engaged in considerations about the kind of work they might do after discharge, had made limited or unrealistic financial plans, had not made any preparations, nor started to plan. Whilst most of these veterans had been afforded the time and opportunity to think and plan for their future, including attending TAP classes, two of these veterans reported that due to their base location or operational tempo prior to discharge, they did not have the time or opportunity (no access to TAP) to think and plan ahead. Three of the veterans had served as reserves following active duty; these veterans consistently reported not being provided the opportunity or encouragement to plan and prepare in addition to not having separation strategy support from programs such as TAP. This had a detrimental impact on transition; these veterans reported feeling unsupported and unknowledgeable about where to access support, benefits, and health care. A defining feature differentiating those who did think ahead from those who had not, were their negative opinions of the TAP program, among three who had attended. The three veterans who were not thinking ahead but had attended TAP mostly reported it as a check box exercise that they viewed as irrelevant and useless. The veterans who had not thought ahead were a mixture of currently employed and unemployed and the majority reported difficulties securing work, not enjoying their work and job role, and still not knowing what they wanted to do. These veterans appeared to lack direction, goal orientation, and a sense of purpose which manifested in an apparent lack of drive and motivation to prepare for their futures or change their current situations, which was in contrast to the veterans who had thought ahead. Among many of those who had not thought ahead and not made 
preparations was the expression and discussion of wishing they had made preparations and considerations for life after the military.

\section{Living the transition}

Living the transition from military to civilian society meant the veterans, regardless of current employment status, were confronted by barriers that impeded attempts to find and maintain employment. However, some of the veterans found things that facilitated employment and overcame some of the barriers. This master theme therefore comprises two sub-themes: Barriers and Facilitators. These subthemes were derived inductively from the focus group data and are not reflective of pre-exiting categorization from previous studies however, the various barriers and facilitators have been evidenced in existing research but not group in these terms.

Barriers: Three barriers impacted the veterans' ability to find and maintain employment once they had left the military. Twelve of the eighteen veterans reported a "culture clash" with civilians which made maintaining employment difficult and in the most extreme cases led to poor mental health, alcohol use, and loss of jobs. The culture clash included differences in work ethic and communication style, and nostalgia for previous camaraderie and team work. Ten of the veterans across all groups, reported having to "start over" in civilian life such as taking entry level and low paying jobs, returning to education, and gaining civilian certifications in things they were trained to do in the military. Starting over not only created practical barriers, but also had a psychological impact on self-esteem and mood. Some veterans reported feeling frustrated they should be finding success in their life post military service, not having to start over. A challenge in translating military roles, skills and experiences to civilian roles appeared to be a key factor in determining to what degree veterans had to start over. Many of the veterans who had thought ahead were prepared for and realistic about having to start over, thus easing this barrier to employment. 
Four veterans, from employed group three, and one veteran from the unemployed group, reported believing employers discriminate against veterans, especially those with combat experience. However, three of the veterans who believed this reported other factors, such as physical health complaints or limited experience that may also have hindered their chance of success.

Facilitators: The majority of the veterans discussed things that had helped them not just with employment but more broadly in managing transition. Being connected with other veterans via veteran support groups, organizations and programs; having veteran supportive employers with organized veteran groups; being in contact with the peers they served with; and, working for veteran organizations or with veteran clients, provided support, camaraderie, and shared experiences that helped ease the culture clash and also connect to possible employers. Though over just over half of the veterans reported attending job fairs and using the internet in their job search, it was evident that having veteran connections provided more fruitful links to employers and knowledge about job vacancies, enabling several veterans to find work.

Social support from family and friends was also reported as being invaluable, providing moral and practical support as well as helping some veterans "stay on track" when tempted to follow peers in maladaptive coping such as alcohol use. Use of available support services such as Volunteers of America and other local Chicago veteran groups had enabled veterans to find employment both through practical assistance (such as skills translation assistance) but also via the connections it provided to other veterans. A final facilitator was having the ability to adapt to civilian work and the culture clash and find new purpose and meaning in their civilian life and work. Being cognitively flexible and able to adapt enabled veterans to manage frustrations with 
civilian work culture, such as adapting their expectations of civilian work ethic, changing their communication style, and finding job roles that involved team work and a sense of camaraderie.

\section{Discussion}

Focus groups were conducted with 14 employed veterans across three focus groups and four unemployed veterans in one focus group, in the Chicago Metropolitan area to understand the veterans' experiences of finding and maintaining employment after leaving military service. Thematic analysis of focus group data led to the development of two master themes that represent the temporal nature of transition to civilian employment: Pre-transition; and, Living the transition.

\section{Pre-transition}

Veterans who had "thought ahead", had more positive experiences finding and maintaining civilian employment compared to those who had not thought about or made plans for life after military service. Those who had not thought ahead and had attended TAP reported it was not useful and that it was a box checking exercise. Service members simply being present at TAP may not be enough to aid successful civilian employment. Service members must be ready and willing to engage in the contents. The findings from this study indicate that only those who had already started to think about their future reported engaging and benefitting from it. Thus, whilst TAP may be a useful and worthwhile program for those thinking ahead, there may be many who are not ready to think ahead, for whom TAP may be a futile process. Arguably, TAP may need to include an initial stage that aims to assist soon-to-be transitioning service members in igniting their

thoughts about their future. Some veterans were not able to attend TAP due to their military base location and/or operational tempo prior to discharge. Service personnel should be afforded the time and space to access TAP to enable their planning and preparations for civilian employment, 
regardless of their location, operational tempo, and service status (Active Duty or Reserve/National Guard).

The important role thinking ahead plays in finding and maintaining employment after military service is clear. Through the process of considering new roles, applying for jobs, and having college places confirmed, the veterans were engaging in what Ebaugh (1988), termed "seeking alternatives" and "bridging activities", respectively. Consistent with the current study, Ebaugh (1988) found that those who were thinking ahead via seeking alternatives and engaging in bridging activities, adjusted to role transitions with more ease. This is also consistent with research conducted with veterans in the UK, which found that having goals for civilian life, especially employment, led to more successful transitions (Jolly, 1996). Knowing what they wanted to do and making considerations about their civilian employment could be understood as the veterans showing what Ryan and Deci (2000) term self-determination, which led to the motivation to make preparations and plans.

\section{Living the transition}

Cultural differences between the military and civilian society created employment barriers due to clashes in communication, work ethic, and team work. Employment barriers due to militarycivilian cultural differences have been reported elsewhere in the literature (Atuel et al., 2016; Shields et al., 2016; Smith \& True, 2014). The change in work ethic and environment can make civilian employment and life seem alienating and frustrating. Military cultural norms clash with civilian norms (Smith \& True, 2014) and can be problematic since we derive pride and self-esteem from the affirmation of shared experiences and group membership (Tajfel, 2010). It is not surprising that some veterans in this study reported that their experience of the cultural clash led 
to alcohol use, mental health difficulties, and even termination of employment (in some cases by the veteran and others the employer).

Feeling they were having to start over was an employment barrier for some veterans practically but also psychologically, this has been reported elsewhere in the literature (Kintzle et al., 2015; Smith \& True, 2014). Veterans who had thought ahead and were prepared seemed less impacted by this barrier compared to those who had not. It is possible that this is associated with their lack of engagement with the TAP program which most of the veterans who were unprepared had either not attended or had not engaged with.

Perception of employer discrimination was a barrier reported by some veterans. Existing literature examining the possible existence of employer discrimination against veterans is limited and inconclusive, but indicates that veteran hiring may differ by race and military experience (Kleykamp, 2009). It is possible that some veterans may take a discrimination based interpretation of their lack of success in securing jobs. This is consistent with research investigating attribution errors and a tendency to make discrimination attributions (e.g. sexual or racial) to protect selfesteem (Major, Quinton, \& Schmader, 2003). A discrimination rhetoric may be used as a coping mechanism protecting veterans from acknowledging personal barriers such as their physical health. This is especially pertinent in the context of research highlighting the impact transition to civilian life can have on veterans' sense of status, identity, and purpose, which in turn effects selfesteem (Jolly, 1996; Smith \& True, 2014). The presence and impact of potential employer discrimination towards veterans requires further investigation.

The veterans in this study who had thought ahead appeared generally better equipped to deal with the barriers. Further to the positive impact of thinking ahead, being veteran connected seemed to help veterans adapt to civilian culture clashes and make contacts that in some cases led 
to employment. The positive impact of peer support for transitioning veterans in terms of encouraging the use of support services and overcoming barriers to seeking help has been reported elsewhere in the literature (Greden et al., 2010), this could be true in terms of employment, where veterans learn from each other about which support services to use and may encourage each other to use available resources. Psychologically, connecting with other veterans may help ease the cultural clash and provide a space where they can connect with others who share in the same language and experience helping to increase self-esteem (Smith \& True, 2014), as well as allow them to share experiences of how to adapt and cope in civilian society. Accessing available social support from family and friends assisted many of the veterans manage transition The positive impact of social support is well documented in the literature (Cohen \& Wills, 1985; Osborne, 2012), thus veterans should be encouraged to connect with social support systems prior to leaving service, especially connecting with other veterans.

It has been proposed, in previous research, that culture should be central to understanding transition since the development of new cultural skills and understanding are important for adaptation to civilian life (Ray \& Heaslip, 2011). This was evident in the current study, where those who had found ways to adapt to civilian work ethic and communication, had found civilian jobs that involved team work and a shared common goal, and had found purpose in civilian work, reported positive experiences of their employment.

\section{Implications}

The results of this focus group study lead to practice, policy and future research implications. The practice and policy implications can be understood temporally as being proactive and reactive methods to assist veterans in finding and maintaining employment. Proactively, the TAP program requires adaptation to include methods that encourage veterans' to start to think 
about the future so they engage with and benefit from the full program. This might be in the format of recently transitioned veterans presenting at mandatory pre-TAP classes informing soon to transition personnel of the realities of transition and finding civilian employment, and ways TAP and other preparations can help. Methods that increase self-determination could also improve veterans chances at finding and maintaining employment. Using a motivational interviewing approach in a pre-TAP class could assist in motivating veterans to plan for their future. The important role of self-determination in making career changes might also be applicable to nonveteran populations in the process of adapting or changing their careers (Blustein \& Flum, 1999).

TAP should also include education about the challenge of adapting to civilian culture and methods to assist adjustment such as encouraging them to connect with other veterans, available social support, and veteran support services. TAP classes should aim to create realistic expectations of life after the military and the need to be prepared so they are able to adapt. Finally, TAP should be available to all military personnel due to leave service regardless of base location, operational tempo, and service status (Active Duty, Reserve, or National Guard).

Reactively, those working with and providing services to veterans in various capacities should be aware of the nuanced employment needs veterans have. As well as the practical challenges of deciding what work they want to do, translating skills, and attending interviews, for example, a military-civilian divide exists which makes veteran-civilian communication and understanding sometimes challenging. Employers being military/veteran culturally competent and veterans being civilian culturally competent could go some way in assisting veterans adapt to the civilian work environment and for civilian employers and colleagues adapt to work with veterans.

Having a job that has purpose and a collective goal assisted many veterans in being able to both maintain and enjoy their employment. Careers counselling for veterans should move past 
matching skills with available jobs, to encouraging veterans to consider the kind of work they would like to do. Taking constructivist and solution-focused career counselling approaches may aid this process (Miller, 2004). Having volition over their employment and having career goals should increase self-determination (Ryan \& Deci, 2000) in turn increasing motivation and drive to overcome employment barriers and adapt to their new civilian working environment, encourage connection to support services, other veterans, and other methods of reaching their career goals.

Future research should focus on investigating the presence and impact of employer discrimination and the possible use of a discrimination rhetoric as a coping mechanism. In the event that any adaption to the TAP program were implemented, these adaptations, such as a preTAP class should be evaluated for its effectiveness in assisting veterans not only find and maintain employment but have a successful transition to civilian life.

\section{Limitations}

The sample being from the Chicago Metropolitan area, means these findings may not be generalizable to veterans residing in other areas of the US. Location of veterans is likely to impact employment experiences due to availability of support services, economic climate, and types of available jobs. The difficulty recruiting participants and the low attendance rate at focus groups, may have impacted group dynamics and discussions. Attendance at focus groups was likely biased by the downtown Chicago location which can be expensive to park, although participants were compensated $\$ 30$ for attendance, parking costs were reportedly approximately $\$ 40$. For one of the focus groups, only two participants, out of an expected eight, attended the group. The inclusion of this "group" in the final data set was discussed by the researchers. Since the themes that arose from the analysis of this group were consistent with those from the other focus groups, the data was deemed to be useful and of good quality in accordance with the credibility and dependability 
criteria of evaluating qualitative data (Lincoln \& Guba, 1985), and was therefore included in the study.

The qualitative focus group approach of this study is a strength, using this method furthered understanding of veteran's employment experiences, moving past a purely practical focus to include the psychological and cultural challenges and facilitators. The study also emphasizes the challenges of employment maintenance, not just acquisition, such as the impact of the culture clash.

\section{Conclusions}

Using a qualitative focus group method, this study highlights the temporal nature of the barriers and facilitators veterans experience in their endeavor to find and maintain civilian employment. Prior to leaving service, personnel should be encouraged to engage in considerations about their future and make plans for their civilian employment, including engaging in, not just attending, TAP programs. On entry to civilian life, veterans are likely to be faced with barriers to employment, such as translating their skills to civilian job roles, managing the cultural clash of civilian work environments, and employer discrimination. Veterans may overcome these barriers by connecting with other veterans, using available social support and support services, and having volition over their future career goals. Additions to the TAP program, service provision, and ways to minimize the military-civilian cultural divide, may go some way in assisting veterans with these challenges, proactively and reactively.

\section{References}

Atuel, H. R., Keeling, M., Kintzle, S., Hassan, A., \& Castro, C. A. (2016). Veteran employment in the 21 st century. In L. Hicks, E. Weiss, \& J. E. Coll (Eds.), The civilian lives of U.S. veterans: Issues and Identities (Vol. 1). Santa Barbara, C.A. : Praeger. 
Barrera, C., \& Carter, P. (2017). Challenges on the Home Front: Underemployment Hits Veterans Hard. Retrieved file:///C:/Users/mkeeling/Downloads/ZipCODE_Vet_Report_FINAL.pdf

Blustein, D. L., \& Flum, H. (1999). A self-determination perspective of interests and exploration in career development Vocational interests: Meaning, measurement, and counseling use. (pp. 345-368). Palo Alto, CA, US: Davies-Black Publishing.

Braun, V., \& Clarke, V. (2008). Using Thematic Analysis in Psychology. Qualitative Research in Psychology, 3(2), 25.

Bureau of Labor Statistics. (2016). Employment Sitaution of Veterans - 2015: News Release. U.S. Department of Labor

Carter, P., Schafer, A., Kidder, K., \& Fagan, M. (2017). Lost in translation: The Civil-Military divide and Veteran employment. Retrieved from https://www.cnas.org/publications/reports/lost-in-translation

Castro, C. A., Kintzle, S., \& Hassan, A. (2014). The State of the American Veteran: The Los Angeles County Veterans Study. . Retrieved from

Castro, C. A., Kintzle, S., \& Hassan, A. (2015). The State of the American Veteran: The Los Angeles County Veterans Study. Retrieved from Los Angeles: cir.usc.edu.

Cohen, S., \& Wills, T. A. (1985). Stress, social support, and the buffering hypothesis. Psychological Bulletin, 98(2), 310-357. doi:10.1037/0033-2909.98.2.310

Department of Defense. (2015). United States Department of Defense Fiscal Year 2016 Budget Request: Overview.

Department of Defense. (2016). DoDTAP: Transition Assistance Program. Retrieved from https://www.dodtap.mil/core curriculum.html

Ebaugh, H. R. F. (1988). Becoming an Ex: The Process of Role Exit. Chicago: The University of Chicago Press.

Greden, J. F., Valenstein, M., Spinner, J., Blow, A., Gorman, L. A., Dalack, G. W., . . Kees, M. (2010). Buddy-to-Buddy, a citizen soldier peer support program to counteract stigma, PTSD, depression, and suicide. Annals of the New York Academy of Sciences, 1208(1), 9097. doi:10.1111/j.1749-6632.2010.05719.x 
Hamilton, A. B., Williams, L., \& Washington, D. L. (2015). Military and mental health correlates of unemployment in a national sample of women veterans. Med Care, 53(4 Suppl 1), S3238. doi:10.1097/mlr.0000000000000297

Horton, J. L., Jacobson, I. G., Wong, C. A., Wells, T. S., Boyko, E. J., Smith, B., . . Millennium Cohort Study, T. (2013). The impact of prior deployment experience on civilian employment after military service. Occupational and Environmental Medicine, 70(6), 408417. doi:10.1136/oemed-2012-101073

Jolly, R. (1996). Changing step: From military to civilian life: People in transition. London: Brassey's.

Kintzle, S., Keeling, M., Xintarious, E., Taylor-Diggs, K., Munch, C., Hassan, A. M., \& Castro, C. A. (2015). Exploring the economic and employment challenges facing U.S. veterans: A qualitative study of Volunteers of America service providers and veteran clients. . Retrieved from Los Angeles, CA. :

Kleykamp, M. (2009). A great place to start? The effect of prior military service on hiring. Armed Forces and Society, 35(2), 20.

Lincoln, Y. S., \& Guba, E. G. (1985). Naturalistic Inquiry. Newbury Park, CA: Sage Publications.

Loughran, D. S. (2014). Why is veteran unemployment so high? (0833085344). Retrieved from https://www.rand.org/pubs/research_reports/RR284.readonline.html

Major, B., Quinton, W. J., \& Schmader, T. (2003). Attributions to discrimination and self-esteem: Impact of group identification and situational ambiguity. Journal of Experimental Social Psychology, 39(3), 220-231. doi:http://doi.org/10.1016/S0022-1031(02)00547-4

Miller, J. H. (2004). Extending the Use of Constructivist Approaches in Career Guidance and Counselling: Solutionfocused Strategies. Australian Journal of Career Development, 13(1), 50-59. doi:10.1177/103841620401300108

Osborne, J. W. (2012). Psychological effects of the transition to retirement. Canadian Journal of Counselling and Psychotherapy, 46(1), 13.

Prudential. (2012). Veterans' Employment Challenges: Perceptions and experiences of transitioning from military to civilian life. Retrieved from http://www.prudential.com/documents/public/VeteransEmploymentChallenges.pdf 
Ray, S. L., \& Heaslip, K. (2011). Canadian military transitioning to civilian life: a discussion paper. J Psychiatr Ment Health Nurs, 18(3), 198-204. doi:10.1111/j.13652850.2010.01652.x

Rudstam, H., Strobel Gower, W., \& Cook, L. (2012). Beyond yellow ribbons: Are employers prepared to hire, accommodate and retain returning veterans with disabilities? Journal of Vocational Rehabilitation, 36(2), 87-95.

Ryan, R. M., \& Deci, E. L. (2000). Self-determination theory and the facilitation of intrinsic motivation, social development, and well-being. American Psychologist, 55(1), 68.

Shields, D. M., Kuhl, D., Frender, J., Baurmann, N., \& Lopresti, P. (2016). Mental health and well-being of military veterans during the military to civilian transition: Review and analysis of the recent literature. Retrieved from https://cimvhr.ca/documents/R2CLPVVC-Health-and-Wellbieng.pdf

Smith, R. T., \& True, G. (2014). Warring Identities: Identity Conflict and the Mental Distress of American Veterans of the Wars in Iraq and Afghanistan. Society and Mental Health. doi:10.1177/2156869313512212

Tajfel, H. (2010). Social identity and intergroup relations: Cambridge University Press.

Zivin, K., Yosef, M., Levine, D. S., Abraham, K. M., Miller, E. M., Henry, J., . . Valenstein, M. (2016). Employment status, employment functioning, and barriers to employment among VA primary care patients. J Affect Disord, 193, 194-202. doi:10.1016/j.jad.2015.12.054 